CP, 2013 , N²2, pp. 54-63. ISSN 2014-6752. Girona (Catalunya). MARTINS MESQUITA, Aline y FERRÉ PAVIA, Carme: LA FAMÍLIA HOMOPARENTAL EN LA FICCIÓ TELEVISIVA: LES PRÀCTIQUES NARRATIVES DEL BRASIL I D’ESPANYA COM A RELATS DE LES NOVES REPRESENTACIONS AFECTIVO-AMOROSES.

Recibido: 28/02/2013 - Aceptado: 22/04/2013

\title{
LA FAMÍLIA HOMOPARENTAL EN LA FICCIÓ TELEVISIVA: LES PRÀCTIQUES NARRATIVES DEL BRASIL I D'ESPANYA COM A RELATS DE LES NOVES REPRESENTACIONS AFECTIVO-AMOROSES
}

\author{
Homoparental family on television fiction: Narrative practices in Brazil and \\ Spain as stories of the new representations affective-loving
}

\author{
Autoras: MARTINS MESQUITA, Aline y FERRÉ PAVIA, Carme \\ Grup de recerca en Comunicació i Responsabilitat Social \\ Comress-Incom UAB (www.comress.org) Universitat Autònoma de Barcelona \\ Edifici I Campus UAB 08193 Bellaterra Tel. 935811939 \\ alinemartinsm@gmail.com / carme.ferre@uab.cat
}

\section{Resumen}

\begin{abstract}
This paper discusses the treatment of the homoparental family on television fiction in Brazil and Spain. Interdisciplinarity is evident among family, society and fiction productions. The research focuses on an analysis of the family homoparental on television productions Hospital Central (Spain) and Páginas da Vida (Brazil). Through a content textual analysis, the attributes of each family are elucidated. In total, 228 sequences were selected from both works, with a pre-selection of 197 chapters and about 10,000 minutes assisted. The results confirm the representation articulated between desire and tradition in relationships and the tendency of the television production to avoid the homosexual stereotype, breaking the heteronormative contract. The study also confirms the potential television has as a tool that unites the affective-loving new representations of couples. Despite the different sociolegal context, a balance concerned to screen presence of the characters is detected. The emancipatory narrative practice of the Spanish series and the deeper treatment of a homosexual couple is different to the Brazilian soap opera. The later one shows a restricted approach-loving and affectionate father-son. The research provides a historical and contextualized social work and offers elements for a new field of study: the homoparental family on television..
\end{abstract}

\section{Key words}

Gay and lesbian family, parent-child relationhips, television and social change, narrative practice in television
Este artículo analiza el tratamiento de la familia homoparental (de progenitores del mismo sexo) en las series de ficción de las televisiones de Brasil y España. A través de una muestra de 197 capítulos, con un total de unos 10.000 minutos de observación empírica, se estrajeron 228 secuencias de interés de la serie Hospital Central (España) y la telenovela Páginas da Vida (Brasil), donde se analizan los atributos de una familia homoparental de cada obra y se aborda el análisis textual de su contenido, en cuanto a narrativas y temas planteados. Los resultados confirman el potencial de la televisión como herramienta que consolida las nuevas representaciones afectivo-amorosas y muestra una representación que articula deseo y tradición en las relaciones. Se concluye la diversa tendencia de estas obras a evitar el estereotipo homosexual, rompiendo con el contracto heteronormativo.

Independientemente del contexto sociolegal distinto, se detecta un equilibrio de presencia en pantalla de los personajes. Pero la práctica narrativa de la serie española es emancipadora y su tratamiento de una pareja homosexual es profundo y diferente al de la telenovela brasileña, en la que se detecta restricción en los abordajes afectivo-amoroso y paternofilial. Esto aporta datos contextualizados de manera histórica y social a un campo de estudio que se abre como futuro y novedoso: la imagen de la familia homoparental en los medios de comunicación.

\section{Palabras clave}

Familia gay y lesbiana, relaciones paternofiliales, televisión y cambio social, práctica narrativa en televisión 


\section{Introducció}

La societat actual mostra obertament noves formes de relació, nous contractes socials i entre persones i nous codis de relació i conducta. Però malgrat això, és important esbrinar els límits d'aquestes realitats quant a la representació de les relacions afectivoamoroses. Els avenços socials de la contemporaneïtat estableixen una relació estreta amb la representació de la intimitat, com a evolució d'allò que Giddens denomina "sexualitat plàstica" (2004: 12), desfeta dels lligams de la reproducció, orientada al plaer i a la sexualitat com un espai on es filtra la negociació.

Segons Roudinesco (2003), aquest és un canvi que va un generar "desordre" en l'organització social i en la família. La institució familiar ha viscut estadis: la família tradicional, que va assegurar la transmissió d'una herència, sense que la vida sexual i emocional dels esposos, units generalment ben joves, es tingués en compte; la segona fase és la família "moderna", basada en l'amor romàntic, on s'estableix la divisió del treball entre els cònjuges, i finalment, la família "contemporània", que uneix dues persones per les seves relacions íntimes o en la cerca de satisfacció sexual.

"La transferència d'autoritat és cada vegada més problemàtica, a mesura que divorcis, separacions i recomposicions conjugals augmenten" (Roudinesco, 2003: 19). L'autora reformula Rousseau per mostrar la importància de la família com la societat més antiga, i l'única natural:

La família és, si es vol conceptualitzar, el primer model de les societats polítiques: el cap és la imatge del pare, el poble és la imatge dels nens i, tot haver nascut lliures i iguals, no alienen la seva llibertat, excepte per necessitat personal (2003: 3, traducció pròpia).

La qüestió de la constitució de la família i del parentesc s'està redefinint, i és palès en els marges de la societat o en les situacions especials (Fonseca, 2008). Som conscients que moltes vegades les idees o conductes que han estat discriminades es desplacen al centre de la cultura popular. Allò que era marginal pot esdevenir una força i un mirall del canvi social. A la televisió, a les telenovel·les i a les sèries de ficció, en general, veiem com un camp de joc popular mostra el canvi cultural en allò que afecta al parentiu.

En cap moment de la història han estat tan visibles públicament a la televisió el protagonisme de les dones, la liquidació de la família convencional, l'aparició de noves formes de convivència i les noves performances de gènere. Les trames serials de televisió són les principals mediacions per representar o recrear el fenomen (Martín Barbero, 2002). Quan analitzem la formació de la família i la construcció del parentiu a les obres de ficció contemporània, o fins a quin punt es van distanciar $o$ no del paradigma convencional de la família nuclear tradicional (formada per pare, mare i fills), podem dir que la biologia continua sent el nucli de l'afinitat dels productes televisius, però amb alguns matisos novells.

Coincidim amb Martín Barbero que, en general, el disseny dels mitjans de comunicació, especialment la televisió, revela un procés de mediació, és a dir, opera en tots els nivells de les relacions humanes. En aquest sentit, són centrals, ja que potencien la quotidianitat de les persones.

Prenem com a exemple el nostre objecte d'estudi la família homoparental -o família homo-afectiva- en la ficció televisiva, que si d'una banda costat qüestiona l'ordre heteronormatiu, de l'altra altra és capaç de ratificar-lo (Butler, 2000; Carver \& Chambers, 2007; Martínez-Conde, 2012).

Tot i que el seu impacte encara és insignificant en les trames televisives en general, en la perspectiva del tractament aprofundit de les representacions afectivo-amoroses i dels seus aspectes correlacionats, com ara la paternitat/maternitat i l'educació dels fills, aquest tipus de relat està començant a ser discutit als programes de televisió i guanya força en l'espai mediàtic (Ramírez \& Cobo, 2013).

Per això, fomentem un debat sobre els possibles canvis en els valors $\mathrm{i}$ les representacions de gènere $\mathrm{i}$ la sexualitat, a partir de la imatge de la família homoparental, presentada en la sèrie de ficció espanyola Hospital Central (Telecinco: 2000-) i en la telenovel·la brasilera Páginas da Vida (Rede Globo: 
2006/2007). Aquestes obren aborden el desafiament particular de la televisió de projectar una societat en mutació compromesa amb la diversitat (Martins Mesquita, 2012), sense oblidar-nos del pluralisme de gènere o sexual en la televisió, defensat per Ferré Pavia (2010).

A més del fet que Hospital Central és una sèrie de ficció espanyola de gran durada, aquesta producció ens crida l'atenció sobre l'enfocament natural d'una relació homosexual formada per dues dones que treballen a un hospital, que volen tenir fills i que contrauen matrimoni davant un jutge. Aquest fet va ser emès el
2005, el mateix any en què Espanya va reconèixer legalment el matrimoni entre persones del mateix sexe. Seguint aquesta cronologia, busquem en la telenovel-la Páginas da Vida, a través de la parella formada per dos homes, un interessant cas de la inserció d'una família estable homoparental a la televisió brasilera, que també va acompanyar els canvis legals en el terreny amorós. Aquesta telenovel-la complementa el nostre univers de recerca: en el seu enfocament pioner, encara que poc aprofundit, a la televisió oberta del Brasil.

\section{Objectius}

En aquest estudi volem assolir els següents objectius específics:

A. Proporcionar elements teòrics i metodològics per crear un camp d'estudi acadèmic que investiga la família homoparental en la ficció televisiva.

B. Investigar la inserció i el tractament de dues famílies homoparentals: una present a la trama de la sèrie espanyola Hospital Central i l'altra en la telenovel-la brasilera Páginas da Vida, per tal d'identificar les diferències en les relacions afectivo-amoroses dels personatges i els seus vincles paternofilials.

C. Confirmar que la televisió, a través de sèries de ficció i de les telenovel-les, actua com un mapa interpretatiu d'un món construit a partir de la realitat, analitzant els valors afectivo-amorosos que transmet.

\section{Marc teòric: la relectura de la convivència}

Diversos autors han afirmat que la institució familiar occidental s'ha convertit en un fenomen complex per la seva estructuració diferent, que van donar lloc a canvis importants en les normes socials i sexuals (Castells, 1999; Roudinesco, 2003; Giddens, 2004). Avui dia, la família, constituïda ontològicament en base al plaer, fa front a un desconcert causat per l'allunyament dels valors tradicionals per la falta d'una llei simbòlica i d'una regla paterna, i per la tendència cap a l'adaptació dels costums a les necessitats modernes (Roudinesco, 2003).

\subsection{Lleialtats en conflicte}

En aquest sentit, la família tradicional nuclear formada per pare, mare i fills va ser desafiada pels canvis que Occident ha promogut, especialment en el segle XVIII, quan va sorgir el feminisme, que "amb l'adveniment de la burgesia, va transformar la família en una cèl-lula biològica que va donar lloc central a la maternitat" (Roudinesco, op.cit., p.11, traducció pròpia). Sorgeix, llavors, una nova llei familiar "tot permetent que les dones reafirmessin la seva diferència, que els nens fossin mirats com a subjectes i que els invertits es normalitzessin" (íbid).

De aquesta manera, el patriarcat va ser un dels primers elements de l'estructura social a ser testimoni de aquests canvis. Segons Castells (1999), el patriarcat posa en relleu l'autoritat i la força simbòlica dels homes sobre les dones i els seus fills en el context de la família. L'impacte dels moviments socials, especialment el feminisme, en les relacions de gènere va provocar una ona expansiva: es va fixar l'heterosexualitat com a norma. Segons l'autor, per les dones homosexuals, la separació dels homes com a subjectes de l'opressió que sofrien era la conseqüència lògica de la certesa que "el domini masculí era la font dels problemes de les dones" (Martins Mesquita, 2012:46).

Pel que fa als homosexuals masculins, el debat entre la família nuclear clàssica i els problemes relacionats 
amb els homes i les dones significava "una oportunitat per explorar altres formes de relacions interpersonals, incloses noves formes de família, les famílies gais" (Castells, 1999:162). Seguint el pensament de l'autor, l'alliberament sexual va tornar a ser un element de la manifestació personal, desvinculat amb la visió homòfoba i promíscua, prioritzant la sexualitat i l'amor i, sobretot, l'autoafirmació.

Per a l'autor, als anys noranta es va poder observar la pèrdua de força de la família patriarcal, principalment en els països de Primer Món. Un indici de l'afebliment d'un model de família tradicional era, segons Castells, la separació o el divorci de la parella. L'autor fins i tot considera la possibilitat d'una reproducció del patriarcat però en un context diferenciat. Malgrat això, afirma que les relacions internes, com les de confiança, es veuen sense gaire força per l'experiència, tant de les dones com dels nens, lligats pel que l'autor titlla de "lleialtats en conflicte" (Castells, op. cit., p.163).

No es tracta, per tant, de rols fixos i immòbils, sinó de funcions i llocs a ocupar, d'acord amb la dinàmica d'aquesta família que té un objectiu final: assegurar que al final del procés hi haurà un subjecte amarat de valors sobre l'educació i la vida social. D'una manera particular, també obtenir satisfacció, amb un desig que es manifesta en la voluntat (Bauman, 2007). Aquesta és l'herència que cal esperar d'una família, independentment de la manera com està estructurada.

\subsection{La nova família en les televisions del Brasil i de l'Estat espanyol}

Al Brasil el Cens Demogràfic 2010, de l'Instituto Brasileiro de Geografia e Estatística - IBGE, va constatar que el país té més de 60.000 parelles del mateix sexe. Al 2011 una decisió del Tribunal Superior Federal va suposar un gran canvi en la història legislativa del país sud-americà, un dels més homofóbics del món ${ }^{2}$. Fins a quinze anys va haver d'esperar el col·lectiu homosexual d'aquest país per portar a votació el projecte de Parceria Civil

\footnotetext{
1 Destaquem que l'IBGE és el més gran proveïdor de dades i informacions estadístiques del Brasil. Disponible a: <http://www.ibge.gov.br/home/>. Accés: 11 de setembre de 2011.

2 D'acord amb el reportatge, cada dos dies un homosexual era assassinat al Brasil. Disponible a:

$<$ http://gazetaweb.globo.com/v2/noticias/texto_completo.php?c=19884 6>. Accés: 26 d'octubre de 2011.
}

Registrada, ja que en el passat, per la polèmica que suscitava entre els senadors federals, no es va fer mai efectiva.

Per a les parelles formades per persones del mateix sexe i fins que no va ser aprovada la unió homosexual al Brasil, l'única opció legal que tenien per reconèixer la seva unió era sotmetre's a contractes de parella de fet. L'aprovació de la nova llei permet a les parelles homosexuals adoptar criatures. Malgrat això, segons diu l'Instituto Brasileiro de Pesquisas-IBOPE, més de la meitat de la població brasilera (55\%) no aprovava la unió entre parelles del mateix sexe. S'obtenien els mateixos resultats quan se'ls preguntava per la possible adopció de criatures per part de parelles d'aquest perfil. Restava, per tant, un $45 \%$ de la població que es mostrava tolerant amb la nova família. La investigació va posar en relleu que en tots dos casos, el rebuig cap a les causes homosexuals és més gran entre els homes, els evangèlics, els més grans, les persones menys escolaritzades i d'estrats socials més baixos, que malauradament són majoria en aquest país (Figueiredo Santos, 2011).

Pel que fa a la societat espanyola, tot sembla indicar que hi ha un ajustament cap a les possibilitats familiars que desafien les bases de la seva estructura. Hi ha més de 22.000 casaments gais celebrats a Espanya fins al 2012, d'acord amb l'Institut Nacional d'Estadística.

A la televisió de tots dos països la nova família va guanyar relleu paral-lelament per les conquestes del col-lectiu homosexual (Mira, 2007). Al 2005 el reconeixement de la llei d'unió homosexual, a Espanya, va incidir gairebé de manera immediata en l'argument narratiu de la sèrie Hospital Central, en la qual els personatges Maca i Esther oficialitzen la seva unió davant d'un jutge, en la trama fictícia. La parella va protagonitzar debats sobre maternitat, inseminació artificial, educació dels fills, i fins i tot el bateig. Una pràctica narrativa consistent $i$ reveladora de l'experiència homosexual com no s'havia vist abans a la televisió espanyola, malgrat de les innombrables insercions de personatges homosexuals en la ficció d'aquest país, especialment des dels anys 80 , quan noves i transgressores representacions, fins i tot de la dona, van començar a aparèixer (Sáez Mateu, 2008).

A Catalunya, per exemple, la sèrie $E l$ cor de la ciutat (TV3: 2000-2009), de perfil familiar, és un referent pel tracte transgressor que va donar a la relació 
homosexual que existia entre dos dels personatges que formaven part del repartiment, inimaginable fa vint anys:

"És igualment obvi que aquest tractament ja partia d'un canvi social previ que el feia mediàticament assumible o tolerable" (Sáez, 2008: 52).

Altres sèries de la televisió catalana, com Jet Lag (TV3: 2001-2006), comptaven amb la participació regular de personatges homosexuals. En el cas de Jet Lag, la narrativa presentava, amb un enfocament positiu, una lesbiana rude que va optar per ser mare.

Pel que fa a Espanya, encara que amb uns estereotips molt marcats, van començar a aparèixer personatges homosexuals a la ficció televisiva de manera regular a partir de l'any 2000; per citar algunes sèries, hi ha el cas de Siete Vidas (Telecinco: 1999:2006) i Aquí no hay quien viva (Antena 3: 2003-2006).

En el cas brasiler, en el mateix mes en què el tribunal brasiler va aprovar el casament homosexual, la televisió d'aquest país va mostrar una escena històrica: un petó entre dues dones, tal com al 2003 ho havia estat a un serial diürn nord-americà (Harrington, 2003; Ng, 2008). El 12 de maig de 2011 els telespectadors del canal SBT van assistir al petó entre Marina i Marcela, personatges de la telenovel-la Amor e Revolução (SBT: 2011/2012). Aquesta obra de ficció va ser la primera a concebre i a retransmetre una escena de petó gai -que ja és tot un mite en la televisió brasilera- sense interferències.

L'escena d'un petó homosexual va ser escrita per l'emissora Rede Globo, per a la novel-la América al 2005. Els personatges masculins van gravar el petó però malgrat això, l'escena va ser prohibida i mai emesa. El mateix va succeir amb un altra novel·la, Duas Caras, al 2007, ja que esdevindria un petó entre els personatges masculins després de la seva unió civil. Basada en els Princípios de Qualidade de la TV Globo, l'emissora va argumentar que no emetria "beijos gays e carícias".

\section{Disseny metodològic}

Els pressupostos teòrics i metodològics que sustenten aquesta investigació, essencialment qualitativa, es nodreixen d'elements de la narratologia, la teoria dels textos narratius, per analitzar els factors de interès d'aquest text televisiu empíric, des del punt de vista del seu contingut. Segons Bal (1990), un text narratiu està composat pel text en si mateix, per una història i una faula. Correspon a aquesta investigació el text narrat a la sèrie Hospital Central i a la telenovel-la Páginas da Vida, amb els seus esdeveniments relacionats amb els personatges elegits, en representació d'unitats semàntiques completes. En aquesta perspectiva narrativa, s'estudia essencialment el que es diu en el text, i no com es diu. Inevitablement es fa una incursió en disciplines relacionades, com ara la sociologia, la psicologia i la sexualitat per analitzar personatges i contextos en qüestió, ampliant el ventall de característiques valorables.

\subsection{Mostra i model d'anàlisi}

El corpus d'anàlisi triat foren les sèries de ficció Hospital Central i de la telenovel·la Páginas da Vida, en base a l'articulació entre gènere (drama), presència regular d'una família homoparental (relació estable) i protagonisme (personatges centrals en la mostra seleccionada). La visualització dels capítols de les dues obres va permetre identificar dades qualitatives sobre el tractament de la família homoparental en la ficció televisiva, amb una voluntat comparativa. Es cercaven les característiques d'una família homoparental, formada per dues dones, Maca i Esther (família homoparental 1 - Espanya), i d'una altra formada per dos homes, Marcelo i Rubinho (família homoparental 2-el Brasil).

L'observació empírica abasta 197 capítols, dividits en 28 capítols d'Hospital Central (temporada $9 / 10=25$ capítols; temporada $11,12,13=3$ capítols) i 169 capítols de Páginas da Vida, amb un total d'uns 10.000 minuts analitzats. Basant-nos en Casetti \& Di Chio (1999: 240), desenvolupem l'anàlisi del contingut de les obres a partir d'una mostra predeterminada, tenint en compte els capítols estudiats, els fenòmens d'interès, identificats i seleccionats en forma de seqüències d'interès, enumerades de l'1 a la 228. Es van localitzar les referències de l'anàlisi, i amb el seu 
minutatge final, quan es tracta de les parelles estudiades. En els següents gràfics representem una mostra de les seqüències d'interès de l'estudi, i, a continuació, les dades addicionals de l'anàlisi realitzada i informacions generals sobre cada obra:

\section{Gràf. 1. Models - Seqüències d'interès}

Temporada 10 - Capitol 13 (144) "O calle para siempre" (Hospital Central)

151. (01:08:12) Maca és la primera en arribar al jutjat. Esther arriba tot seguit. Els pares de la pediatra apareixen, per sorpresa, al casament. Maca els repi els porta als seus seients separats, on està la mare de l'Esther. Estan tots els amices l'hospita.

Pare: ¿Sabias que ibamos a veni?

Yace No pero Esther se ha empeñado en dejarlos (os assentos) libres ( $O$ pai cumprimenta Esther)

Jutge: Macarena, ; consientes en contraer matrimonio con Esther?; Eres consciente de que lo contraes en este acto? vasis $\sin$

Jas

Jutge: Por la potestad que me confiere en el cargo que ostento, os declaro legalmente casadas (Seg̣ue a sequûencia e Teresa

Ther

\section{BRASI}

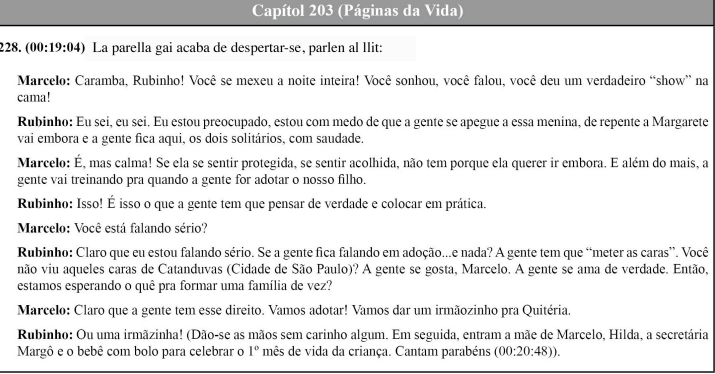

Font: Elaboració pròpia

Gràf. 2. Especificitats - Hospital Central i Páginas da Vida

\begin{tabular}{|l|c|c|}
\cline { 2 - 3 } \multicolumn{1}{l|}{} & HOSPITAL CENIRAL & PAGINAS DA VIDA \\
\hline PAÍS & Espanya & Brasil \\
\hline EMISSOR & Telecinco & Rede Globo \\
\hline INICI D'EMISSIÓ & 2000 & 2006 \\
\hline FINAL D'EMISSIÓ & - & 2007 \\
\hline GÈNERE & Sèrie de ficció & Novel-la \\
\hline MICROGÈNERE & Drama hospitalari & Melodrama \\
\hline HORARI & Prime time & Prime time \\
\hline PERIODICITAT & Setmanal & Diari \\
\hline DURACIÓ/CAPÍTOL & $70{ }^{\prime}$ & $40^{\prime}$ \\
\hline SEQÜÈNCIES D'INTERÈS & 165 & 63 \\
\hline CAPÍTOLS ESTUDIATS & 28 & 169 \\
\hline TEMPORADES ESTUDIADES & $9,10,11,12,13$ & - \\
\hline TEMPS ESTUDIAT (min.) & 2080 & 8120 \\
\hline PARELLA HOMOSSEXUAL & Maca i Esther & Marcelo i Rubinho \\
\hline
\end{tabular}

Font: Elaboració pròpia
Ens basem en Igartua (1998) per fixar els aspectes més rellevants dels personatges pel que fa als atributs morfològics (descripció física i característiques corporals) i als atributs funcionals (aspectes psicològics o trets de la personalitat, comportaments i temes) que presenten els personatges de la narrativa seriada.

Tots dos atributs presenten dades importants per a l'anàlisi dels perfils socials abordats. Més enllà, ampliarem la investigació dels atributs narratius, relacionats amb els aspectes propis de la narració televisiva, com ara la presència en pantalla. D'aquesta manera, respectarem les abreviacions emprades per a la fitxa referencial de la nostra anàlisi:

AM- Atributs morfològics (dels personatges);

AF- Atributs funcionals (dels personatges, temes i el seu entorn);

AN - Atributs narratius (de la presència dels personatges en pantalla).

Les categories generals i metodològiques per a l'anàlisi es divideixen:

-Parella homosexual 1 (Maca i Esther)

-Parella homosexual 2 (Marcelo i Rubinho)

-Relació amorosa tradicional (representativa de normes socials dominants)

-Relació amorosa no tradicional (no representativa de normes socials dominants)

-Qualificacions dels personatges i de les seves relacions

-Temes abordats per les parelles

Conflictes entre la parella i la relació paternofilial.

La fitxa d'anàlisi textual estableix les característiques corporals o trets de personalitat (comportaments) comuns dels personatges. El fet de marcar un sèrie limitada de trets facilita un reconeixement estereotipat per part les audiències (Montero Rivera, 2005). La caracterització psicològica avaluarà els trets de major incidència en els personatges. Per a això s'ha marcat unes categories de sociable, passiva, poderosa, agressiva, gelosa o responsable. També s'anoten valors morals, temperament, aptituds, actituds i qualitats, com ara ser introvertit o extrovertit. Pel que fa a les 
emocions, se'n marcaran quatre de bàsiques: alegria, por, ràbia i tristesa (Galán \& Herrero, 2011; Igartua et al., op.cit.).

Marcats aquests atributs, pautarem trets funcionals (psicològics) que complementen la llista, relacionats a estats, disposicions i aspectes socials (Iraegui \& Quevedo, 2002). Per posar-ne exemples, aquests trets poden ser: amable, decidit, dialogant, elegant, generós, intel·ligent, nerviós, respectuós, seriós o seductor.

El repertori temàtic haurà de ser relacionat amb els conflicte que els personatges protagonitzen les parelles analitzades. Com van afirmar Galán \& Herrero:

"Las buenas historias provienen de grandes conflictos: el miedo, el amor, la soledad, los secretos, los deseos inalcanzados... Cuanto más universal sea este conflicto, más fácil será la identificación con el público" (op. cit. p. 95).

Els conflictes seleccionats per al nostre treball estan basats en els que poden ser considerats de caràcter universal.

També considerem les característiques socials dels personatges, com ara estrat social, educació, oci, vida familiar, cultural i professional. Amb les característiques definides, els principals elements metodològics es mostren en una fitxa referencial (gràfic 3):

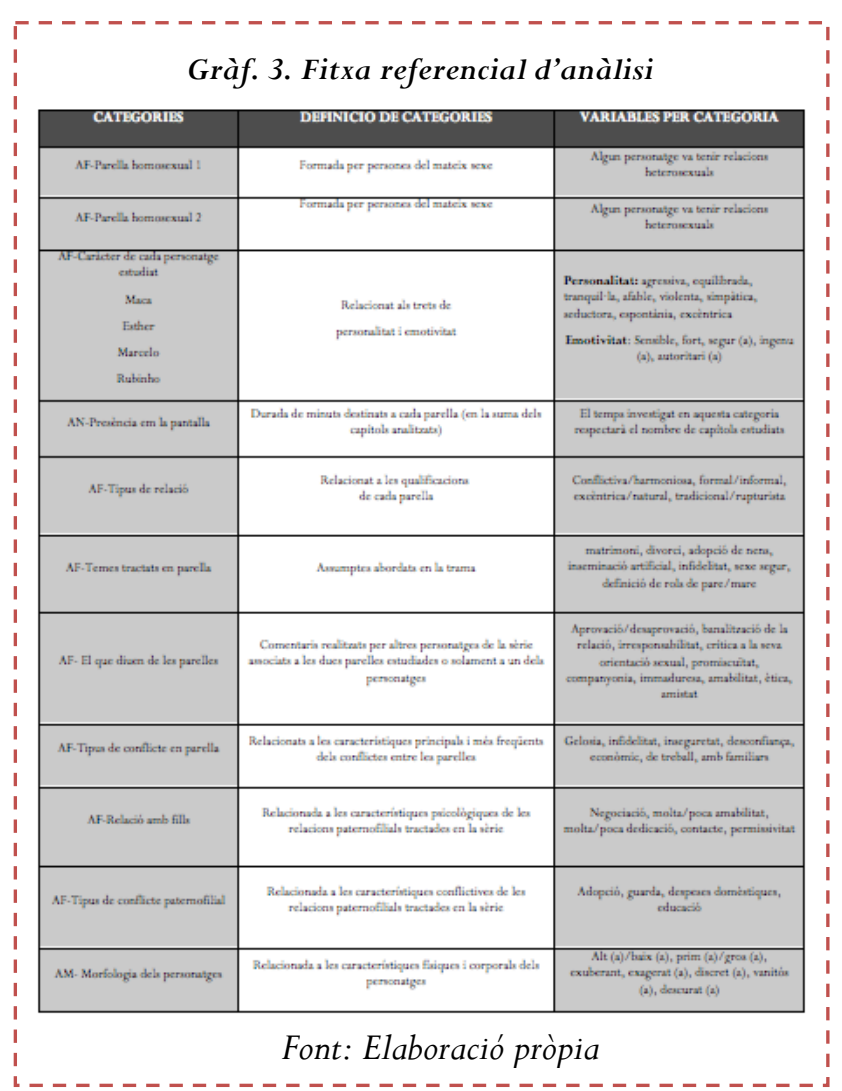

\section{Resultats: perfils i diferències de les parelles homosexuals}

En referència als nostres objectius anteriorment explicitats, en el trajecte teòrico-conceptual realitzat $\mathrm{i}$ en les anàlisis de la mostra de la investigació, destaquem el paper de la televisió com a espai de relacions dialògiques, identifiquem característiques importants en els perfils de les dues parelles homosexuals estudiades i la pràctica emancipadora de la sèrie Hospital Central, a través de la família homoparental 1 , a diferència de la limitació d'aprofundiment del vincle afectivoamorós i de les relacions paternofilials detectada com a família homoparental 2, de Páginas da Vida.

En l'observació empírica de la mostra pròpia, quantifiquem que, en dues temporades, la família homoparental 1 va obtenir una mitjana de 60 minuts de presència en la pantalla. En el cas de la família homoparental 2 va coincidir en la televisió en poc més de 58 minuts, el que posa en manifest, sota la nostra opinió, un equilibri significatiu de la representació dels dos universos narratius estudiats. Però la parella espanyola és central en la trama, a diferència de la parella brasilera, que només va començar a tenir visibilitat a la telenovel-la a partir del capítol 32.

Un altre punt de discrepància es detecta pel que fa a la quantitat de seqüències d'interès obtinguda per cada parella: 165 per la parella espanyola i 33 per a la brasilera, el que confirma el protagonisme i la introducció dels fils narratius dels personatges estudiats en la sèrie espanyola.

Seguint la lògica metodològica establerta pels atributs morfològics dels quatre personatges estudiats: Maca i Esther (família homoparental 1), i Marcelo i Rubinho (família homoparental 2) 
relacionats amb les seves característiques físiques i corporals, es destaquen l'ús de actors i actrius de bona imatge i atractius, el que podria arribar a ser un estereotip comú en la ficció en general.

Els personatges estudiats van mostrar, cadascun, trets peculiars que els caracteritzen de diferents maneres. La pediatra Maca era més reservada i afectuosa; la infermera Esther semblava ser més espontània i extrovertida. El dermatòleg Rubinho va resultar equilibrat i tranquil, i el músic Marcelo era ingenu i sensible. Malgrat les diferències, les dues parelles van ser vinculades a formalitats, com el matrimoni i el desig de reproducció, ratificant la voluntat de sotmetres al model familiar. Van ser models de relació de compromís mutu, confiança i pocs conflictes de parella però sí amb dilemes relacionats a l'acceptació de l'orientació sexual de les famílies.

En moments específics de les trames, els perfils s'assemblen els uns als altres, en un contrast propi de l'ésser humà amb el seu entorn. Un punt d'accent constant va ser el professionalisme, el talent i les amistats de cada parella. No hem identificat cap perfil pejoratiu o vinculat de manera forçada a l'orientació sexual dels personatges. Això revela que la sexualitat no va ser concebuda en les obres com un factor determinant per a la construcció de la personalitat i emotivitat de cada personatge.

El tractament del discurs amorós referent a la família homoparental 1 va tenir històries de fàcil identificació amb els espectadors, encara que amb les limitacions que imposa que les trames passin en una unitat d'emergència d'un hospital. La relació amorosa no tradicional, amb independència de la seva orientació sexual, va tenir un tractament complet, fins a cert punt aprofundit amb petons i carícies, fins $\mathrm{i}$ tot de manera dinàmica. L'autonomia de cada capítol de la sèrie dotava d'una estructura temporal àgil a les històries que es relacionaven amb els subjectes implicats. El punt culminant de la relació es va produir en moments concrets: el casament de dues dones, en l'embaràs per inseminació artificial de la pediatra Maca i en els conflictes de l'educació del nen. Una obra amb un discurs essencialment emancipador.
Ja pel que fa a la família homoparental 2, hem pogut comprovar que es tractava d'una relació estable, encara que informal, amb poca intimitat i carícies. L'únic dilema al qual es referia va ser la decisió de lluitar en els tribunals per l'adopció d'un nen, que només semblava una elecció final de la parella en l'últim capítol de la telenovel·la, quan els dos homes, al llit encara que sense escenes de contacte, van dir que tenien el dret per completar la família.

Hem trobat, doncs, un punt clau de diferència entre les dues parelles: el tractament de les relacions paternofilials associades amb cada parella. La primera focalitzava un tema més complex d'encaixar dins de la narració, ambientada en un hospital, amb l'exploració dels conflictes relacionats amb la religió, l'educació, com ara l'embaràs de la dona a través de la inseminació artificial. En relació a l'educació d'un fill en una família homoparental, un exemple de diàleg d'Hospital Central il·lustra l'abordatge referent a la transgressió dels valors tradicionals:

Esther: ¿Te digo la verdad? Yo no bautizaría a Pedro, el sitio me da igual.

Maca: Esther, ya lo hemos hablado, que a mí me da igual, pero para mi madre es la ilusión de su vida y esto es sólo una ceremonia para que esté contenta y nada más.

Esther: Es que no es sólo una ceremonia y tú lo sabes. $A$ ver. Hay que buscar una madrina, un padrino, los trajes, las invitaciones, un catering, la orquestra, porque seguro que habrá orquestra. No sé, buscar un hotel para que se alojen los invitados. No sé, me parece complicarse innecesariamente.

Maca: ¿Y qué quieres que hagamos?

Esther: Si tú quieres lo hacemos, Maca, pero yo dejaría que Pedro creciera, le educaría bien y que él elija cuando sea mayor. Yo.

Maca: Vale, tienes razón y ya me jode que siempre tengas razón, pero muy bien, me parece bien (...).

(Hospital Central: temporada 13 - capítol 8)

Pel que fa a la segona parella, la presentació del tema de l'adopció per part de parelles homosexuals semblava ser l'únic vincle transgressor en relació als dos homes. El naixement de la filla de la 
secretària dels nois va promoure el debat, ja reforçat mitjançant l'incentiu de la mare d'un d'ells perquè la fes àvia. Va ser llavors quan la decisió de la parella va ser que volien i podien adoptar un nen. El discurs és moderat en l'obra brasilera:
Rubinho: Estar com você é sempre a melhor opção. Feliz ano novo, cara! Obrigado por mais esse ano de parceria, de companheirismo, de cumplicidade.

Marcelo: Eu que agradeço. Obrigado por mais esse ano de amor, de paixão.

(Páginas da vida - capítol 156)

\section{Conclusions: el nou diàleg entre el desig i la tradició a la ficció}

Les dues obres de ficció d'aquest estudi reforcen la tendència actual dels processos afectivo-amorosos en els quals els vincles estan basats en la reconstrucció d'una llei comuna, encara que visiblement influenciats per aspectes tradicionals d'una relació afectiva. Van ser verificades una subjectivitat i una intimitat liderades pel desig, amb una norma interna encara per definir.

Reconeixem que, en estudiar la família homoparental, així com l'heterosexual, no es pot oblidar el cultiu d'una interioritat que doni contingut a les relacions, de cònjuge o no, casats o en un enamorament passatger: "Centrar-nos excessivament en el matrimoni pot fer que ens oblidem que, possiblement, com a estructura, estigui supervaloritzada" (Martins Mesquita, 2012: 337 traducció pròpia). Preferim fer ús del concepte de "família plàstica", concebut per Sáez (2008b), que reitera el que es va verificar en el trajecte teòric d'aquesta investigació: las relacions i els vincles, en aquest context de diversitat formal i llibertat individual, guanyen en sinceritat però també en fragilitat. Investigar les noves relacions afectivoamoroses ens mena a aquest concepte, per tal de considerar el caràcter dialèctic i mutable de la família.

Amb referència a la televisió, el repte d'aquesta línia d'investigació té potencial per servir d'antecedent a la creació de projectes culturals de les emissores i canals. Acreditem que és imprescindible que s'actualitzi el compromís social com un objectiu de la televisió en la seva condició de propagadora de valors $\mathrm{i}$ principis. La nostra intenció és crear elements de referència que possibilitin entendre la realitat i buscar promoure la igualtat de tractaments narratius dels personatges, independentment de la seva sexualitat.
En aquest sentit, culturalment, el Brasil fa paleses característiques pròpies $i$ una identitat per a difondre, clarament, un tema com la família homoparental.

La pràctica narrativa i les especificitats verificades a Hospital Central constitueixen un model de normalització de contingut narratiu sobre la família homoparental a la televisió, aplicable al context brasiler. Ratifiquen el potencial investigador d'un camp acadèmic innovador al qual es comença a donar vida: la família homoparental en la ficció televisiva. Un estudi com aquest porta a reflexionar sobre els nous valors en les relacions afectivo-amoroses que emergeixen en la contemporaneïtat $\mathrm{i}$ a debatre sobre la disseminació d'aquests valors i els seus models en les narratives televisives.

Destaquem, fins i tot, la construcció d'una estructura de recerca rellevant per a la consolidació d'una línia d'estudi acadèmica enfocada cap a la família homoparental en la ficció televisiva, atesa l'escassetat d'estudis que aprofundeixen la relació entre família, sexualitat i representació en la ficció.

Tal com identifiquem en el treball, la falta de protagonisme de la família homoparental i les seves especificitats, tant a la televisió, de manera general, com a l'univers acadèmic, el destaquen com un camp fructífer d'investigació. La voluntat és que pugui servir d'antecedent per al disseny d'iniciatives culturals de producció de les cadenes televisives amb valors de pluralisme i justícia. 


\section{Referències}

- BAL, Mieke (1990): Teoría de la narrativa.Una Introducción a la narratología. Madrid, Ed. Cátedra.

- Bauman, Zigmunt (2007): Amor líquido. Acerca de la fragilidad de los vínculos humanos. Madrid, Fondo de Cultura Económica de España.

- BUTLER, Judith (2000): Antigone's Claim: Kinship between Life \& Death. Nova York, Columbia University Press.

- CARVER, Terrell F.; CHAMBERS (2007), Samuel A. "Kinship Trouble: Antigone's Claim and the Politics of Heteronormativity", a Politics and Gender, n³ (4) 12, pp. 427-449.

- CASETTI, Francesco; DI CHIO, Frederico (1999): Análisis de la televisión. Barcelona, Paidós.

- CASTELlS, Manuel (1999): La era de la información. Vol 2. El poder de la identidad. Madrid, Alianza Editorial.

- FERrÉ PAVIA, Carme (2010): "Pluralisme i mitjans de comunicació, per un pacte necessari”. La Catalunya Plural. Fundació CatDem. Disponible: <http://www.catdem.org/cat/downloads2/la-catalunyaplural.pdf>. Accés: 11 abril 2012.

- FigueIREDO SANTOS, José Alcides (2011): "Desigualdade racial de saúde e contexto de classe no Brasil”, a Dados, $\mathrm{n}^{\circ} 54$, pp. 5-40.

- FONSECA, Claudia (2008): "Homoparentalidade: novas luzes sobre o parentesco", a Revista Estudos Feministas, $\mathrm{n}^{\circ} .16$, pp. 769-783.

- GALÁN, Elena; Herrero, Begoña (2011): El guión de ficción en televisión. Madrid: Síntesis.

- GALÁN, Elena; HeRrero, Begoña (2011): El guión de ficción en televisión. Madrid: Síntesis.

- GIDDENS, Anthony (2004): La transformación de la intimidad. Sexualidad, amor y erotismo en las sociedades modernas. Madrid, Cátedra.

- HARRINGTON, C. Lee (2003): "Homosexuality on All My Children: Transforming the Daytime Landscap", a Journal of Broadcasting and Electronic Media, $\mathrm{n}^{\circ} 478$ (2), pp. 216-235.

- IGARTUA, Juan José (et al.) (1998): Indicadores culturales y construcción de estereotipo en filmes de ficción. Fundación Infancia y Aprendizaje. Madrid.

- IRAegui, Ana; QUeVedo, María Paz (2002): Aproximación psicolingüística al estudio de la personalidad en español: una propuesta taxonómica. Madrid: Iberpsicología, $\mathrm{n}^{\circ}$ 7, pp. 1-3.

- MARTÍN BARBERO, Jesús (2002): “Jóvenes, comunicación e identidad”, a Revista de Comunicação e Cultura, $\mathrm{n}^{\mathrm{o}} \quad 102002 . \quad$ Disponible: <http://www.oei.es/pensariberoamerica>. Accés: 10 gener 2010.

- MARTÍNEZ-CONDE BELUZÁN , Macarena (2012): ¿Nuevas familias? Explorando el potencial distintivo de construcciones discursivas en situaciones de homoparentalidad. Tesi doctoral. Universitat Autònoma de Barcelona, Bellaterra.

- MARTINS MESQUiTA, Aline (2012): A família homoparental na ficção televisiva: As práticas narrativas do Brasil $e$ da Espanha como relatos das novas representações afetivoamorosas. Tesi doctoral. Universitat Autònoma de Barcelona, Bellaterra.

- MIRA, Alberto (2007): De Sodoma a Chueca. Una historia cultural de la homosexualidad en España en el siglo XX. Madrid, Editorial Egales S.A.

- MONTERO RIVERA, Yolanda (2005): "Estudio empírico sobre el serial juvenil $\mathrm{Al}$ salir de clase sobre la transmisión de valores a los adolescentes". Televisión de calidad: Congreso Hispanoluso de Comunicación y Educación. Huelva. Disponible: <http://dialnet. .unirioja.es/servlet/ articulo?codigo=2925916>. Accés: 7 maig 2012.

- NG, Eve (2008): "Reading de Romance of fan culture production. Music videos of a television lesbian couple”, a Popular Communication n ${ }^{\circ}$ 6, pp.103-121.

- RAMÍREZ, María del Mar; COBO, Sergio (2013): "La visión gay-friendly en las series de ficción españolas”, a Comunicación y Sociedad, n 19, pp. 213-235.

- ROUDINESCO, Elisabeth (2003): A família em desordem. Rio de Janeiro, Jorge Zahar Editor.

- SÁEZ MATEU, Ferran (2008): Mitjans de comunicació i valors: què volem que siguin els mitjans? Barcelona, Fundació Lluís Carulla, ESADE.

- SÁEZ, Lluís (2008): Família i valors: la institució familiar en temps de canvi. Barcelona, Fundació Lluís Carulla, ESADE.

\section{Forma de Citación}

MARTINS MESQUITA, Aline y FERRÉ PAVIA, Carme: LA FAMÍLIA HOMOPARENTAL EN LA FICCIÓ TELEVISIVA: LES PRÀCTIQUES NARRATIVES DEL BRASIL I D’ESPANYA COM A RELATS DE LES NOVES REPRESENTACIONS AFECTIVO-AMOROSES. Revista Communication Papers, $\mathrm{N}^{\circ}$ 2, páginas 54 a 63. Departamento de Filología y Comunicación de la Universidad de Girona. Recuperado el __ de de 2 de: http://www.communicationpapers.es 